\title{
PENERAPAN METODE INTEGER LINEAR PROGRAMMING PADA PENJADWALAN KARYAWAN
}

\author{
IRSYAD $^{1 *}$, MUHAMMAD RIFAI KATILI ${ }^{2}$, NOVIANITA ACHMAD ${ }^{3}$ \\ 1,2,3 Jurusan Matematika, FMIPA, Universitas Negeri Gorontalo \\ *tamrinirsyad@gmail.com
}

\begin{abstract}
ABSTRAK
Penjadwalan karyawan termasuk masalah yang sering dihadapi pada suatu perusahaan. Makalah ini membahas tentang masalah penjadwalan karyawan menggunakan Integer Linear Programming (ILP) dengan fungsi objektif linear, fungsi kendala linear, dan variabel berupa bilangan bulat. Data penelitian diperoleh dari data primer suatu perusahaan yg terdiri dari jumlah karyawan, jumlah jenis karyawan, dan pembagian shift kerja. Hasil yang diperoleh berupa jadwal karyawan yang menunjukkan efisiensi waktu dan biaya. Penjadwalan karyawan dirancang dalam 2 skenario berbeda dimana kedua skenario menghasilkan jadwal yang berbeda berdasarkan asumsi tapi dengan biaya yang yang dikeluarkan sama. Skenario ini diperoleh tanpa melewati batas waktu yang ditetapkan dan meminimumkan biaya pengeluaran. Nilai Optimum yang didapatkan berupa biaya yang dikeluarkan oleh perusahaan untuk upah karyawan berdasarkan kedua skenario tersebut sebesar 124,689,600, ini lebih hemat dibandingkan dengan penjadwalan secara manual. Jadwal yang dihasilkanpun lebih Optimal dibandingkan dengan penjadwalan secara manual dimana semua karyawan mendapatkan pembagian kerja sesuai kebutuhan.
\end{abstract}

Kata kunci: Integer Linear Programming ; Penjadwalan Karyawan

\begin{abstract}
Employee scheduling includes problems that are often encountered in a company. This paper discusses the problem of employee scheduling using Integer Linear Programming (ILP) with linear objective functions, linear constraint functions, and integer variables. Research data obtained from primary data of a company which consists of the number of employees, the number of types of employees, and the division of work shifts. The results obtained in the form of employee schedules that show time and cost-efficiency. Employee scheduling is designed in 2 different scenarios where both scenarios produce different schedules based on assumptions but with the same costs. This scenario is obtained without exceeding the specified time limit and minimizing expenditure costs. An optimum value obtained in the form of costs incurred by the company for employee wages based on both scenarios is $124,689,600$, this is more efficient compared to manual scheduling. The resulting schedule is more optimal compared to manual scheduling where all employees get the division of work as needed.
\end{abstract}

Keywords: Employee Scheduling; Integer Linear Programming 


\section{Pendahuluan}

Pada penjadwalan karyawan, dilakukan pengaturan karyawan yang akan bekerja pada waktu tertentu dan bagian tertentu. Dalam menyusun suatu penjadwalan diperlukan pemikiran yang cukup rumit untuk dapat memetakan sejumlah komponen penjadwalan karyawan (jumlah pekerja, ketersediaan waktu pekerja, dan tempat bekerja) ke dalam timeslot (matriks ruang dan waktu) dengan mempertimbangkan semua batasan yang ada [1]. Penjadwalan yang dilakukan secara manual akan dirasa kurang efektif apabila terbentur dengan keadaan input data yang banyak dan parameter yang kompleks. Selain membutuhkan ketelitian yang sangat tinggi serta estimasi waktu yang relatif tidak sedikit, metode ini juga memungkinkan terjadinya kesalahan. Proses manual dapat menimbulkan masalah seperti ketidakadilan bagi karyawan dan akan berdampak pada pemberian upah untuk karyawan.

Dalam meminimumkan upah yang dikeluarkan perusahaan, penjadwalan karyawan harus dibuat lebih efektif dan realistis, yaitu penjadwalan sistematis yang terintegrasi dengn berbagai komponen penjadwalan, seperti pekerja, jenis pekerjaan, dan pembagian shift kerja. Upah karyawan bersifat penting dan sensitif dalam suatu pekerjaan. Penjadwalan karyawan yang kurang tepat dapat mengakibatkan biaya untuk upah karyawan bisa meningkat. Pembagian shift kerja yang kurang efektif juga bisa menimbulkan masalah sesama karyawan. Agnes Sondita, dkk [2] membuat simulasi penjadwalan karyawan. Everia [3] dan Pratiwi [4] telah berhasil membuat jadwal karyawan dengan meminimumkan pengeluaran untuk upah karyawan menggunakan model Integer Linear Programming dengan bantuan Lingo.

Menurut pengamatan yang dilakukan secara langsung (wawancara pihak CV. Mufidah ATK) bahwa di CV. Mufidah ATK sendiri masih menggunakan proses manual dalam menentukan jadwal karyawannya. Informasi yang didapatkan saat melakukan wawancara Pihak CV. Mufidah ATK antara lain yaitu untuk pembagian jadwal petugas dimana petugas harus masuk selama dua minggu berurut-urut dan libur dua minggu berutut-urut dalam satu bulan. Berdasarkan masalah tersebut, maka diperlukan penjadwalan yang tepat untuk mengoptimalkan jadwal karyawan. Namun, masalah penjadwalan karyawan merupakan masalah yang tidak mudah untuk dipecahkan, karena dalam pelaksanaannya perlu memperhatikan aturan dan batasan. Salah satu yang perlu diperhatikan yaitu pembagian shift serta jadwal yang berisi jadwal waktu masuk dan istirahat pada tiap jenis pekerjaan, sehingga jadwal pekerjaan dimasing-masing jenis pekerjaan tidak bertabrakan. Dari uraian di atas penelitian ini akan menggunakan metode Integer Linear Programming pada kasus penjadwalan di salah satu bagian CV. Mufidah Gorontalo yaitu CV. Mufidah ATK.

\section{Tinjauan Pustaka}

\subsection{Penjadwalan}

Penjadwalan dalam pekerjaan merupakan pengalokasian sumber daya manusia pada suatu tempat kerja tertentu dengan waktu dan tempat yang telah ditentukan dalam melaksanakan pekerjaanpekerjaan yang telah direncanakan untuk mencapai tujuan yang diinginkan oleh perusahaan[5].

Menurut [6], kriteria optimasi dalam proses penjadwalan dapat dikelompokkan menjadi tiga bagian:

1. Kriteria yang berkaitan dengan waktu

Beberapa kriteria yang terkait dengan waktu ialah minimisasi rata-rata flow time (Pembagian Waktu), minimisasi makespan (Kerentangan), dan minimisasi tardiness (Kerugian).

2. Kriteria yang berkaitan dengan biaya.

Kriteria ini lebih menekankan pada unsur biaya dan kurang atau bahkan tidak memperhatikan 
kriteria waktu yang ada sehingga dengan suatu penjadwalan produksi tertentu diharapkan biaya yang minimum.

3. Kriteria gabungan.

Beberapa kriteria optimalitas dapat digabung dan dapat dikombinasi sehingga menjadi multikriteria.

\subsection{Riset Operasi}

Dalam proses pemecahan masalah riset,menurut [7] diperlukan langkah-langkah yang harus dilakukan, yaitu:

\section{Definisi Masalah}

Pada langkah ini terdapat tiga unsur utama yang harus diidentifikasi:

- Fungsi Tujuan: penetapan tujuan untuk membantu mengarahkan supaya memenuhi tujuan yang akan dicapai.

- Fungsi Batasan/kendala: batasan-batasan yang mempengaruhi persoalan terhadap tujuan yang akan dicapai.

- Variabel Keputusan: variabel-variabel yang mempengaruhi persoalan dalam pengambilan keputusan.

\section{Pengembangan Model}

Mengumpulkan data untuk menaksir besaran parameter-parameter yang berpengaruh terhadap persoalan-persoalan yang sedang dihadapi. Taksiran ini digunakan untuk membangun dan mengevaluasi model matematis yang terbentuk.

\section{Pemecahan Model}

Dalam memformulasikan persoalan ini biasanya digunakan model analitis, yaitu model matematis yang menghasilkan persamaan, sehingga dicapai pemecahan yang optimum.

\section{Pengujian Keabsahan Model}

Menemukan apakah model yang dibangun telah menggambarkan keadaan nyata secara akurat. Jika belum, perbaiki atau buat model baru.

\section{Implementasi Hasil Akhir}

Menerjemahkan hasil studi atau perhitungan ke dalam bahasa seharihari agar mudah dimengerti

\subsection{Linear Programming}

Linear Programming merupakan suatu metode yang akan menyelesaikan persoalan dengan beberapa fungsi kendala untuk mencapai tujuan seperti memaksimumkan (keuntungan yang akan dicapai) atau meminimumkan (biaya). Sifat linear memberi arti bahwa seluruh fungsi matematis dalam model ini merupakan fungsi linear, sedangkan programming merupakan sinonim untuk suatu perencanaan. Dengan demikian linear programming merupakan perencanaan aktivitas-aktivitas untuk memperoleh suatu hasil yang optimum, yaitu suatu hasil terbaik dari seluruh alternatif yang memungkinkan[8].

Bentuk standard dari pemrograman linier menurut [9] mempunyai karakteristik sebagai berikut:

1. Seluruh fungsi pembatas nilai ruas kanannya tidak bernilai negatif 
2. Seluruh variabel keputusan tidak bernilai negatif

3. Fungsi tujuan dapat berupa maksimasi atau minimasi

Secara umum pembuatan model program linear melibatkan 3 komponen dasar yang penting yaitu Fungsi Tujuan, Fungsi Kendala, dan Variabel Keputusan.

Bentuk Umum Model Program Linear :

Fungsi Tujuan :

$$
Z=\sum_{j=1}^{n} c_{j} x_{j}=c_{1} x_{1}+c_{2} x_{2}+\ldots+c_{n} x_{n}
$$

Fungsi Kendala :

$$
\begin{gathered}
\sum_{j=1}^{n} a_{i j} x_{j} \leq,=, \geq b_{i} \\
x_{j} \geq 0
\end{gathered}
$$

untuk $i=1,2, \ldots m$ dan $j=1,2, . . n$

Dengan :

$\mathbf{Z}=$ Fungsi Tujuan yang dicari nilai optimalnya (maksimum, minimum).

$\mathbf{C}_{j}=$ Koefisien harga variabel pengambil keputusan dalam fungsi tujuan, atau parameter yang dijadikan kriteria optimasi.

$\mathbf{X}_{j}=$ Variabel pengambil keputusan yang harus dicari atau variabel aktivitas (keluaran atau output)

$\mathbf{a}_{i j}=$ Konstanta variabel aktivitas ke-j dalam pembatas/kendala ke i

$\mathbf{b}_{i}=$ Kapasitas Sumber i (yang berlebih atau terbatas) yang tersedia untuk dialokasikan ke setiap unit kegiatan.

\subsection{Integer Linear Programming}

Menurut [8], integer linear programming merupakan suatu pemrograman linear yang sebagian atau semua variabel yang digunakan merupakan integer tak negatif. Ada 3 jenis IP yaitu:

1. Pure integer programming (PIP), jika suatu IP menggunakan semua variabel yang berupa integer.

2. Mixed integer programming (MIP), jika suatu IP menggunakan sebagian saja variabel yang integer.

3. 0-1 IP, jika suatu IP menggunakan variabel 0 atau 1.

Integer Linear Programming (ILP) adalah sebuah Pemrograman Linear dimana variabel $x_{j}$ terbatas pada integer.

Model dari ILP sebagai berkut:

Maksimumkan/minimumkan :

$$
Z=\sum_{j=1}^{n} c_{j} x_{j}
$$

Kendala :

$$
\sum_{i=1}^{m} \sum_{j=1}^{n} a_{i j} x_{j}(\leq=\geq) b_{i}
$$




$$
x_{j} \geq 0 \text {, integer untuk } i=1, \cdots, m
$$

ILP digunakan untuk mencari nilai integer dari variabel keputusan yang mengoptimalkan fungsi objektif namun tetap memenuhi fungsi kendala. Bila variabel $X_{i}$ hanya dapat bernilai 0 atau 1 maka ILP tersebut dinamakan zero-one linear programming. Zero-one linear programming memiliki bentuk optimasi sebagai berikut :

minimum:

$$
\begin{gathered}
z(x)=c_{1} x_{1}+\cdots+c_{n} x_{n} \\
a_{11} x_{1}+\cdots+a_{1 n} x_{1} \geq b_{1} \\
\vdots \\
a_{m 1} x_{1}+\cdots+a_{m n} x_{1} \geq b_{m}
\end{gathered}
$$

Variabel keputusan pada zero-one linear programming bernilai 0 atau 1.

\section{Metode Penelitian}

Penelitian ini didahului dengan mengumpulkan data Penunjang. Data yang digunakan dalam penelitian ini adalah data primer. Metode pengumpulan data yang digunakan adalah menggunakan Metode Wawancara dan Metode Observasi.

1. Metode Interview (Wawancara), yaitu mengadakan wawancara langsung dengan pihak CV. Mufidah ATK. Data yang diperoleh antara lain : jumlah karyawan, jumlah jenis pekerjaaan, serta pembagian shift kerja.

2. Metode Observasi, Teknik pengumpulan data, dimana peneliti melakukan pengamatan secara langsung ke objek penelitian untuk melihat dari dekat kegiatan yang dilakukan.

Tahapan dan prosedur penelitian dilakukan dengan:

1. Identifikasi Masalah dan Kriteria Penjadwalan

2. Simulasi Numerik.

3. Interpretasi dan Kesimpulan

\section{Hasil dan Pembahasan}

\subsection{Deskripsi Masalah}

Dalam mendeskripsikan masalah penjadwalan karyawan di suatu perusahaan harus diketahui aturan-aturan yang berlaku di tempat tersebut. Faktor yang menjadi kendala dalam penjadwalan karyawan antara lain ialah banyaknya karyawan yang tersedia di perusahaan tersebut, banyaknya hari bertugas karyawan, banyaknya karyawan yang dibutuhkan untuk setiap jenis pekerjaan, dan berbagai faktor lainnya. Faktor-faktor tersebut harus benar-benar diperhatikan dalam pembuatan suatu model penjadwalan agar sistem dapat berjalan lancar dan tidak menimbulkan berbagai macam masalah, seperti pegawai yang tidak mendapat hari libur atau pegawai yang tersedia tidak mencapai batas minimum sehingga konsumen yang datang tidak terlayani dengan baik. Oleh karena itu, perlu dibentuk 
suatu model penjadwalan yang dapat mengoptimumkan sumber daya yang ada dan tetap memperhatikan berbagai faktor yang mempengaruhinya.

Setiap perusahaan akan memiliki aturan yang berbeda dalam menjadwalkan karyawannya. Berikut ini adalah gambaran dari penjadwalan karyawan di CV. Mufidah ATK, pada umumnya di CV. Mufidah ATK buka setiap hari mulai hari senin-minggu yang terdapat dua shift dalam sistem penjadwalan karyawannya yaitu shift pagi (pagi-sore) dan shift sore (sore-malam). Karyawan pria terbagi atas Petugas Supervisor, Helper Barang, Security, Petugas Kebersihan, Penjaga Parkir, dan Penjaga Penitipan Barang. Karyawan Wanita terbagi atas Sales Promotion Girl, Administrasi, Supervisor,dan Kasir. Fungsi objektif dari permasalahan ini adalah meminimumkan upah karyawan yang dikeluarkan oleh pihak CV. Mufidah ATK. Kendala atau aturan dalam model penjadwalan ini adalah :

1. Kebutuhan Karyawan pada shift pagi dan shift sore setiap harinya terpenuhi

2. Karyawan hanya bertugas satu shift yaitu shift pagi atau shift sore disetiap harinya

3. harus ada sejumlah Kasir yang sesuai dengan jumlah mesin kasir pada setiap Shift

4. harus ada 3 petugas Security dan 1 Petugas Penjaga Penitipan barang pada setiap shift

5. Petugas Security yang bertugas di shift pagi tidak akan bertugas di shift sore

6. untuk semua petugas kecuali petugas Helper barang dan Petugas Administrasi, bertugas maksimal 14 kali di shift pagi dan 14 kali di shift sore

\subsection{Implementasi Model}

Pembahasan masalah penjadwalan karyawan CV. Mufidah ATK dituangkan ke dalam dua skenario. Skenario 1 merupakan model penjadwalan dengan menggunakan aturan yang diinginkan pihak CV. Mufidah ATK, sedangkan Skenario 2 merupakan model penjadwalan yang memodifikasi model penjadwalan pada Skenario 1 dengan memperhitungkan adanya karyawan yang mengajukan cuti pada tanggal tertentu di hari kerja, dengan tetap memperhatikan sumber daya karyawan yang tersedia di CV. Mufidah ATK.

Pihak CV. Mufidah ATK membagi jadwal karyawan menjadi dua shift yaitu shift pagi dan shift sore. Durasi waktu untuk shift pagi adalah pukul 08.00-16.00 dan shift sore pukul 14.00-22.00 . khusus petugas security durasi waktu untuk Shift Pagi adalah 06.00-18.00 dan shift sore adalah 18.00-06.00. Karyawan yang harus dijadwalkan waktu kerjanya adalah petugas Kasir, petugas SPG, petugas Administrasi, petugas Helper Barang, petugas Cleaning Service,Petugas Parkir, petugas Security, petugas Penitipan Barang, dan petugas Supervisor. Total karyawan di CV. Mufidah ATK adalah 103 orang yang terdiri atas 24 orang petugas Kasir, 51 orang petugas Kebersihan SPG, 5 orang petugas Administrasi, 3 orang petugas Helper Barang, 4 orang petugas Cleaning Service, 2 orang petugas Penitipan Barang,2 orang Petugas Supervisor Pria , 6 orang petugas Supervisor Wanita dan 6 orang petugas Security.Penjadwalan karyawan CV. Mufidah ATK ini akan dibuat per 28 hari.

Skenario 1 Pada skenario pertama ini akan dimodelkan masalah penjadwalan sesuai dengan keinginan pihak CV. Mufidah ATK, yakni karyawan hanya bertugas satu shift disetiap harinya. Untuk sistem masuk karyawan kecuali Petugas Administrasi yakni 14 Kali di shift pagi dan 14 kali di shift sore dan untuk petugas Administrasi yakni minimal 14 kali di setiap shiftnya. Kemudian untuk Petugas Security yang bertugas pada shift pagi akan bertugas di shift pagi kembali dihari berikutnya dan Petugas Security yang bertugas pada shift sore akan bertugas di shift sore kembali dihari berikutnya pula. 


\section{Himpunan dan Indeks}

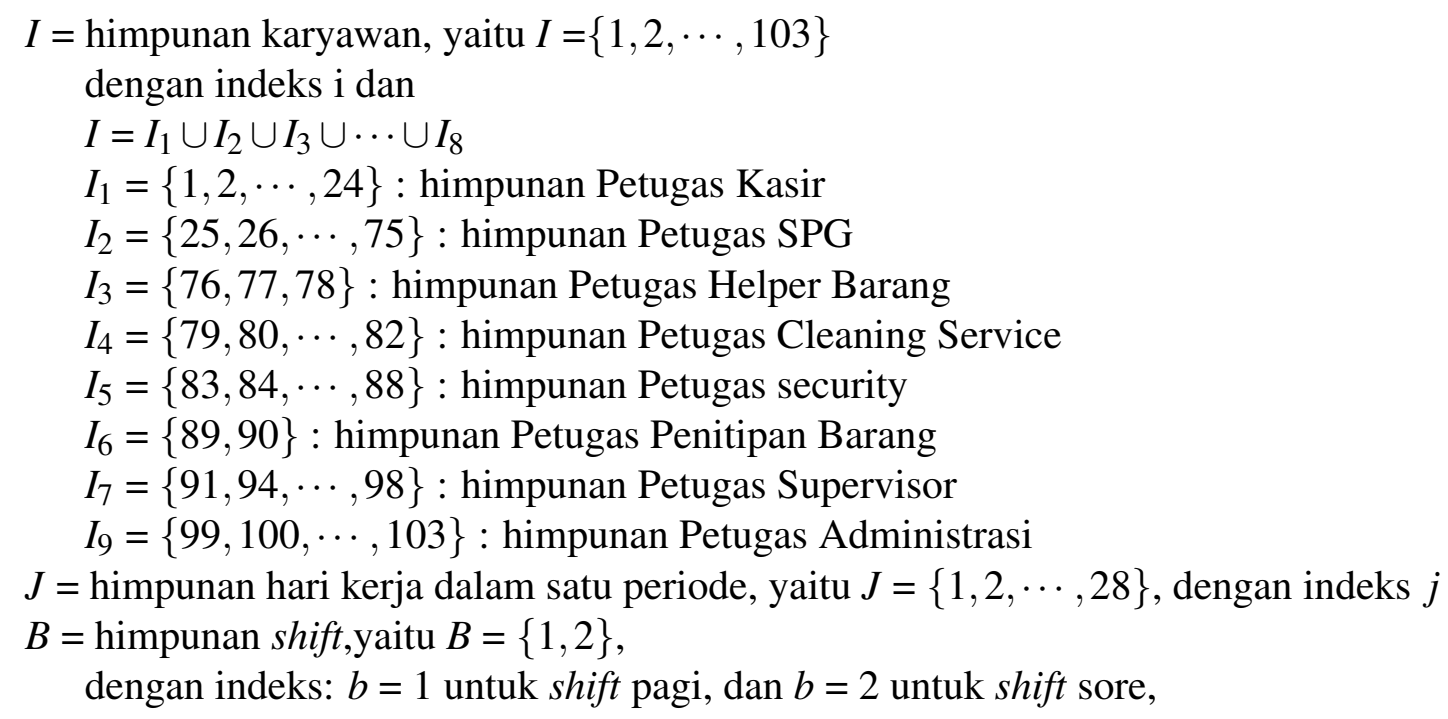

\section{Parameter}

$T O A=$ Banyaknya Kasir, SPG, Administrasi yang harus tersedia disetiap shift $=12$ orang, 25 orang, dan 3 orang.

$T M S=$ Banyaknya Security dan Penitipan Barang yang harus tersedia disetiap Shift $=3$ orang dan 1 orang

$T M C=$ Banyaknya Petugas Helper Barang dan Cleaning service yang harus tersedia disetiap Shift $=2$ orang dan 2 orang

$T S V=$ Banyaknya Supervisor yang harus tersedia disetiap Shift 4 orang.

$O P T=$ Banyaknya hari kerja yang harus dipenuhi oleh setiap karyawan kecuali Administrasi $=$ 14 hari

$O P A=$ Minimal hari kerja yang harus dipenuhi oleh Administrasi dan Helper Barang $=14$ hari

$U S=$ Asumsi Upah perjam yang dikeluarkan pihak Mufidah untuk Security $=3550$

$U A=$ Asumsi Upah perjam yang dikeluarkan pihak Mufidah untuk Seluruh Karyawan Kecuali Security $=5300$

$T P=$ total jam kerja Pada setiap Shift untuk seluruh Karyawan kecuali Security $=8$ jam

$T S=$ total jam kerja Pada setiap Shift untuk Security $=12$ jam

\section{Variabel Keputusan}

$$
X_{b j i}=\left\{\begin{array}{l}
1, \text { jika karyawan i bertugas dihari ke j Shift ke b } \\
0, \quad \text { jika karyawan i tidak bertugas dihari kerja ke j Shift ke b }
\end{array}\right.
$$

Fungsi Objektif Fungsi objektif atau Fungsi Tujuan pada penjadwalan karyawan CV. Mufidah ATK ialah meminimumkan total biaya yang dikeluarkan oleh pihak CV. Mufidah ATK untuk upah 
karyawan, yaitu :

$$
\begin{aligned}
& \min \left[\sum_{j=1}^{28} \sum_{i=1}^{24}\left(\left((8 \times 5300) \times X_{1 j i}\right)+\left((8 \times 5300) \times X_{2 j i}\right)\right)+\sum_{j=1}^{28} \sum_{i=25}^{75}\left(\left((8 \times 5300) \times X_{1 j i}\right)+((8 \times 5300)\right.\right. \\
\times & \left.\left.X_{2 j i}\right)\right)+\sum_{j=1}^{28} \sum_{i=76}^{78}\left(\left((8 \times 5300) \times X_{1 j i}\right)+\left((8 \times 5300) \times X_{2 j i}\right)\right) \sum_{j=1}^{28} \sum_{i=79}^{82}\left(\left((8 \times 5300) \times X_{1 j i}\right)+((8 \times 5300)\right. \\
\times & \left.\left.X_{2 j i}\right)\right)+\sum_{j=1}^{28} \sum_{i=83}^{88}\left(\left((12 \times 3550) \times X_{1 j i}\right)+\left((12 \times 3550) \times X_{2 j i}\right)\right)+\sum_{j=1}^{28} \sum_{i=89}^{90}\left(\left((8 \times 5300) \times X_{1 j i}\right)+((8 \times 5300)\right. \\
\left.\left.\times X_{2 j i}\right)\right)+ & \sum_{j=1}^{28} \sum_{i=91}^{98}\left(\left((8 \times 5300) \times X_{1 j i}\right)+\left((8 \times 5300) \times X_{2 j i}\right)\right)+\sum_{j=1}^{28} \sum_{i=99}^{103}\left(\left((8 \times 5300) \times X_{1 j i}\right)+\left((8 \times 5300) \times X_{2 j i}\right)\right)
\end{aligned}
$$

\section{Fungsi Kendala}

1. Banyaknya Karyawan yang bertugas pada setiap Shift di setiap hari harus memenuhi kebutuhan,

$$
\begin{array}{lll}
\sum_{i=1}^{24} X_{b j i} \geq 12, & \forall b=1,2, \quad \forall j=1,2, \cdots, 28 & \text { (Petugas Kasir) } \\
\sum_{i=25}^{75} X_{b j i} \geq 24, & \forall b=1,2, \quad \forall j=1,2, \cdots, 28 & \text { (Petugas SPG) } \\
\sum_{i=76}^{78} X_{b j i} \geq 2, & \forall b=1,2, \quad \forall j=1,2, \cdots, 28 & \text { (Petugas Helper Barang) } \\
\sum_{i=79}^{82} X_{b j i} \geq 2, & \forall b=1,2, \quad \forall j=1,2, \cdots, 28 & \text { (Petugas Cleaning Service) } \\
\sum_{i=83}^{88} X_{b j i} \geq 3, & \forall b=1,2, \quad \forall j=1,2, \cdots, 28 & \text { (Petugas Security) } \\
\sum_{i=89}^{90} X_{b j i} \geq 1, & \forall b=1,2, \quad \forall j=1,2, \cdots, 28 & \text { (Petugas Penitipan Barang) } \\
\sum_{i=91}^{98} X_{b j i} \geq 4, & \forall b=1,2, \quad \forall j=1,2, \cdots, 28 & \text { (Petugas Supervisor) } \\
\sum_{i=99}^{103} X_{b j i} \geq 3, & \forall b=1,2, \quad \forall j=1,2, \cdots, 28 & \text { (Petugas Administrasi) }
\end{array}
$$

2. Setiap Karyawan hanya mendapat satu Shift dalam satu hari,

$$
\begin{array}{rlr}
X_{1 j i}+X_{2 j i}=1, \quad \forall j=1,2, \cdots, 28, \quad \forall i=1,2, \cdots, 24 & \text { (Petugas Kasir) } \\
X_{1 j i}+X_{2 j i}=1, \quad \forall j=1,2, \cdots, 28, \quad \forall i=25,26, \cdots, 75 & \text { (Petugas SPG) } \\
X_{1 j i}+X_{2 j i}=1, \quad \forall j=1,2, \cdots, 28, \quad \forall i=79,80, \cdots, 82 & \text { (Petugas Cleaning Service) } \\
X_{1 j i}+X_{2 j i}=1, \quad \forall j=1,2, \cdots, 28, \quad \forall i=83,84, \cdots, 88 & \text { (Petugas Security) } \\
X_{1 j i}+X_{2 j i}=1, \quad \forall j=1,2, \cdots, 28, \quad \forall i=89,90 & \text { (Petugas Penitipan Barang) } \\
X_{1 j i}+X_{2 j i}=1, \quad \forall j=1,2, \cdots, 28, \quad \forall i=91,92, \cdots, 98 & \text { (Petugas Supervisor) }
\end{array}
$$


3. Khusus Petugas Helper Barang dan Petugas Administrasi bisa mendapat dua shift dalam satu hari

$$
\begin{aligned}
& X_{1 j i}+X_{2 j i} \geq 1, \quad \forall j=1,2, \cdots, 28, \quad \forall i=76, \cdots, 78 \quad \text { (Petugas Helper Barang) } \\
& X_{1 j i}+X_{2 j i} \geq 1, \quad \forall j=1,2, \cdots, 28, \quad \forall i=99,100, \cdots, 103 \quad \text { (Petugas Administrasi) }
\end{aligned}
$$

4. Total shift Kerja untuk setiap karyawan dalam satu periode,

$$
\begin{array}{lll}
\sum_{j=1}^{28}\left(X_{1 j i}+X_{2 j i}\right) \leq 14, & \forall i=1,2, \cdots, 24 & \text { (Petugas Kasir) } \\
\sum_{j=1}^{28}\left(X_{1 j i}+X_{2 j i}\right) \leq 14, & \forall i=25,26, \cdots, 75 & \text { (Petugas SPG) } \\
\sum_{j=1}^{28}\left(X_{1 j i}+X_{2 j i}\right) \leq 14, & \forall i=79,80, \cdots, 82 & \text { (Petugas Cleaning Service) } \\
\sum_{j=1}^{28}\left(X_{1 j i}+X_{2 j i}\right) \leq 14, & \forall i=83,84, \cdots, 88 & \text { (Petugas Security) } \\
\sum_{j=1}^{28}\left(X_{1 j i}+X_{2 j i}\right) \leq 14, & \forall i=89,90 & \text { (Petugas Penitipan Barang) } \\
\sum_{j=1}^{28}\left(X_{1 j i}+X_{2 j i}\right) \leq 14, & \forall i=91,92, \cdots, 98 & \text { (Petugas Supervisor) }
\end{array}
$$

5. Total shift kerja untuk Petugas Helper Barang dan Petugas Adminstrasi

$$
\begin{array}{lr}
\sum_{j=1}^{28}\left(X_{1 j i}+X_{2 j i}\right) \geq 14, & \forall i=76,77,78 \quad \text { (Petugas Helper Barang) } \\
\sum_{j=1}^{28}\left(X_{1 j i}+X_{2 j i}\right) \geq 14, & \forall i=99,100, \cdots, 103 \quad \text { (Petugas Administrasi) }
\end{array}
$$

6. Setiap Petugas Security yang mendapat Shift pagi bertugas pada Shift Pagi kembali dihari berikutnya. Begitu pula Petugas Security yang bertugas pada shift Sore akan bertugas di shift sore kembali dihari berikutnya,

$$
X_{2 j i} \geq X_{2(j+1) i} \forall j=1,2, \cdots, 27, \forall i=83, \cdots, 88
$$

7. Semua Variabel keputusan ialah integer nol atau satu,

$$
X_{b j i} \in 0,1, \forall b, j, i
$$

Skenario 2 Skenario kedua merupakan modifikasi dari skenario pertama. Perbedaanya dengan skenario pertama ialah adanya karyawan yang mengajukan cuti pada tanggal tertentu dishift pertama dengan asumsi:

1. pengajuan cuti dilakukan sebelum pihak CV. Mufidah ATK melakukan penjadwalan,

2. karyawan hanya dapat mengambil cuti pada shift pertama hanya satu hari dalam satu periode. 
Secara umum, himpunan, parameter, variabel keputusan, dan fungsi objektif pada skenario kedua sama dengan skenario pertama. Dalam skenario kedua terdapat tambahan kendala cuti, yaitu: 10 Karyawan hanya dapat mengambil cuti hanya satu kali dalam shift pertama dalam satu periode,

$$
\begin{array}{rrr}
X_{b j i} & =0, & \forall i=2, \forall j=1 \\
X_{b j i} & =0, & \forall i=4, \forall j=5 \\
X_{b j i} & =0, & \forall i=6, \forall j=11 \\
X_{b j i} & =0, & \forall i=25, \forall j=19 \\
X_{b j i} & =0, & \forall i=45, \forall j=14 \\
X_{b j i} & =0, & \forall i=70, \forall j=11 \\
X_{b j i} & =0, & \forall i=76, \forall j=12 \\
X_{b j i} & =0, & \forall i=82, \forall j=13 \\
X_{b j i} & =0, & \forall i=90, \forall j=5 \\
X_{b j i} & =0, & \forall i=91, \forall j=14
\end{array}
$$

Pada Skenario 1 Rata-rata seluruh karyawan masuk 14 kali di shift pagi dan 14 kali dishift sore hanya ada beberapa jenis karyawan yang masuk lebih dari 14 kali dimasing-masing shift. Solusi yang diperoleh adalah solusi optimum dengan nlai fungsi objektif sebesar 124,689,600 Rupiah. Pada Skenario 2 terdapat perbedaan jadwal bertugas karyawan karena adanya karyawan yang mengajukan cuti pada tanggal tertentu dishift pertama. Biaya yang dikeluarkan oleh pihak CV. Mufidah ATK untuk upah karyawan pada Skenario 1 dan Skenario 2 sama, yaitu sebesar 124,689,600 Rupiah.

\section{Kesimpulan}

Model Integer Linear Programming menghasilkan Skenario penjadwalan yang optimal dengan mempertimbangkan adanya karyawan yang mengambil cuti sebelum pihak CV. Mufidah ATK melakukan proses penjadwalan. Pada Skenario yang dihasilkan upah karyawan yang dikeluarkan bernilai sama dengan jadwal karyawan yang berbeda.

\section{Referensi}

[1] Khalida, S., Jelly, L. \& T Keizerina, D.,2017, 'Penjadwalan Tenaga Kerja untuk menetukan Regular Days Off (RDOs) Menggunakan Algoritma Monroe', Medan, Media Teknika Jurnal Teknologi.

[2] Agnes, S.P., Sudrajat, S. \& R Sudrajat .,2015, 'Simulasi Penjadwalan Pegawai Menggunakan Teknik Integer Linear Programming', Bandung, Departemen Matematika, Fakultas MIPA, Universitas Padjadjaran.

[3] Putri, A.E.,2016, 'Penjadwalan karyawan menggunakan Integer Linear Programming studi kasus di Taman Air Tirtamas Palem Inda Jakarta', Bogor, Departemen Matematika, Institut Pertanian Bogor.

[4] Disti, P., 2015, 'Penjadwalan Pegawai SPBU Menggunakan Integer Linear Programming: Studi Kasus di SPBU 34-16102 Bogor', Bogor, Departemen Matematika, Insitut Pertanian Bogor. 
[5] Dhuha \& Suseno.,2017, 'Penjadwalan tenaga Kerja Untuk Tiga Shift Kerja Dengan Pengembangan Metode Algoritma Tibrewala, Philippe Dan Browne', Aceh,Lhokseumae.

[6] Heizer, J. \& Render, B., 2004, Manajemen Operasi (Terjemahan). Jakarta, Salemba Empat.

[7] Aminudin., 2005, Prinsip-prinsip Riset Operasi. Jakarta, Erlangga.

[8] Winston, W.L.,2004, Operations Research Applications and Algorithms. Ed ke-4, New York (US), Duxbury.

[9] Taha, H.A.,2007, Operations Research: An Introduction. Ed ke-8, Fayetteville (US),Pearson Prentice Hall. 